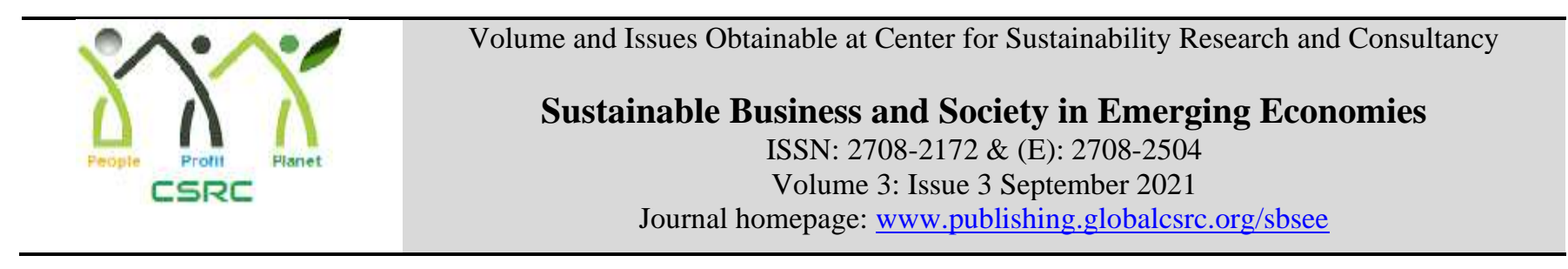

\title{
Measuring the Stressors in Undergraduate Medical Students: A Cross Sectional Study
}

Ayesha Sadiq, The University of Lahore, Punjab, Pakistan

*Muhammad Furqan Ashraf, Department of Sociology, Government College University, Faisalabad, Punjab,

Pakistan

Paris Zakaullah, Department of Sociology, Government College University, Faisalabad, Punjab, Pakistan

Ammara Asghar, Department of Sociology, Government College University, Faisalabad, Punjab, Pakistan

*Corresponding author's email address: furqanashraf882@ gmail.com

ARTICLE DETAILS

History

\section{Keywords}

Stress, Medical Students,

Stressors, Academic Stress.

Jel Classification

A20, A22
Revised format: Aug 2021

Available Online: Sep 2021

\section{ABSTRACT}

Purpose: The purpose of this study is to identify and measure the possible potential stressors among undergraduate medical students and explore the correlation of stress with gender and level of academic year.

Methodology: The cross-sectional study was conducted to identify and measure possible stressors of undergraduate medical students. Data was collected from 243 medical students of Independent Medical College through a questionnaire between august and September 2016. Frequencies and percentages of level of stress were determined through descriptive analysis. Reliability of the MSSQ questionnaire was also checked for possible demographic variations.

Findings: Study proved that the foremost cause of stress experienced by the students was associated to academics that was represented by ARS factor, showing the utmost mean degree off 2. 0453.Females perceive more stress than males in all domains but no significant correlation found on statistical analysis. Level of academic related stress remains same in all levels of academic years whereas IRS, DRS, TLRS, GARS, SRS related stress levels shows progressive reduction from first year to final year.

Implication: Academics related stress is the leading cause of stress in undergraduate medical students, followed by stress related to interpersonal and intrapersonal factors.

(C) 2021 The authors, under a Creative Commons AttributionNonCommercial- 4.0

Recommended citation: Sadiq, A., Ashraf, M. F., Zakaullah, P. and Asghar, A. (2021). Measuring the Stressors in Undergraduate Medical Students: A Cross Sectional Study. Sustainable Business and Society in Emerging Economies, 3(3), 367-373.

\section{Introduction}

Stress is defined as an inability to cope with the pressures generated due to certain situations and circumstances(Brey \& Clark, 2012). This is a well-established phenomenon which is encountered by medical students throughout the world(Nandi, Hazra, Sarkar, \& Mondal, 2012). Medical students are exposed to many stressors during their 5 years stay in a medical college. Stressors are the possible factors 
that can impart stress; they can be related to family, health, academic, psychological, social and emotional issues of an individual(Civitci, 2015); Solanky, Desai, Kavishwar, \& Kantharia, 2012).

Medical students are more prone to develop stress than general population. Several studies revealed that this is related to the hectic routine followed by the medical students along with the large amount of content to be learned(Salam, Yousuf, Muhammad, Bakar, \& Haque, 2013). High levels of stress lead to symptoms of depression, anxiety and lack of confidence in students(Salam et al., 2013).

No certain criterion is there to determine the level and magnitude of stress that can affect, as individuals react differently to different situations. For some people a situation may be stressful but others will respond normally towards it. Therefore it is completely dependent on one's personality and internal abilities that how they perceive and react to certain situations (Ongori and Agolla, 2009).

\section{Significance of the Study}

Focus of this article is on medical student's inability to cope with the pressures generated due to certain situations and circumstances, leading to health issues as well as poor academic performance of the students. Medical students are exposed to many stressors during their 5 years of training. This study is a corner stone to understand the role of different measures of stressors to get a clear picture that how stress effect academic performance correlated with academic year and gender of medical students enrolled in MBBS.

\section{Research Question}

What are the measures of possible potential stressors among undergraduate medical students and explore the correlation of stress with gender and level of academic year?

\section{Research Objectives}

1) To identify the common stressors among undergraduate medical students.

2) To measure the intensity of stressors among different academic years.

3) To study the relationship between gender and stressors.

\section{Materials And Methods}

This is a cross sectional, questionnaire-based study to identify and measure possible stressors in undergraduate medical students. This study was conducted from $1^{\text {st }}$ August 2016 to $1^{\text {st }}$ September 2016 at Independent Medical College, Faisalabad. All the enrolled students from 1st year MBBS to final year MBBS who gave consent were included in this study. A sample size of 243 was calculated using openepi; with a confidence level of $97 \%$.

The Medical Student Stressor Questionnaire (MSSQ) was used in this study, which is a validated instrument to identify sources of stress. The items in MSSQ represent 20 possible sources of stress in medical students identified from the literature grouped into six main factors; Academic Related Stressor (ARS), Intrapersonal and Interpersonal Related Stressor (IRS), Teaching and Learning Related Stressor (TLRS), Social Related Stressor (SRS), Drive and Desire Related Stressor (DRS), and Group Activities Related Stressor (GARS). Respondents were asked to rate each source by choosing from five responses, "causing no stress at all", "causing mild stress", "causing moderate stress", "causing high stress"' and "causing severe stress". The scoring method assigns marks from 0 to 4 to each of the responses respectively.

\section{Data Collection Procedure}

The voluntary students from each class were invited, and particulars concerning the study with respect to rationale, confidentiality and outcome were provided to them. The questionnaire was handed over to the students after proper consent. The participants were requested to respond to all statements in the questionnaire. During time of questionnaire administration, the investigator provided proper guidance and assistance to the participants whenever needed. 


\section{Data analysis}

Analysis of data is done using SPSS version 20. Descriptive analysis of levels of stress in all six main factor domains was done, stratified by gender variation and level of academic years and inculcated in the form of frequency \& percentages of subjects having that level of stress. Reliability of the questionnaire was also checked and found reliable.

\section{Results and Discussions}

A total of 245 questionnaires were distributed to the respondents, out of which 243 questionnaires were filled and 2 were missing providing a response rate of $99 \% .120(49.2 \%)$ of the total respondents were female students and $123(50.4 \%)$ were male students.

To test the reliability of the responses Cronbach's Alpha value was calculated, the result showed up more than $90 \%$ consistency in the responses; hence the instrument was found fit for the research (Table 1). On the basis of this analysis it is concluded that MSSQ is a reliable tool to identify sources of stress among undergraduate medical students.

Table No 1.

Reliability Statistics

\begin{tabular}{|l|l|}
\hline $\begin{array}{l}\text { Cronbach's } \\
\text { Alpha }\end{array}$ & N of Items \\
\hline .916 & 20 \\
\hline
\end{tabular}

Table No.2

Domain, Score and Descriptive Statistics

\begin{tabular}{|l|l|l|l|l|l|}
\hline & $\mathrm{N}$ & Minimum & Maximum & Mean & Std. Deviation \\
\hline ARS & 243 & 1.00 & 3.00 & 2.0453 & .65714 \\
GARS & 243 & 1.00 & 3.00 & 1.6667 & .58916 \\
SRS & 243 & 1.00 & 3.00 & 1.5638 & .58832 \\
IRS & 243 & 1.00 & 3.00 & 1.7202 & .59255 \\
DRS & 243 & 1.00 & 3.00 & 1.7531 & .70765 \\
TLRS & 243 & 1.00 & 3.00 & 1.6255 & .55641 \\
Valid N & 243 & & & & \\
\hline
\end{tabular}

Score interpretation 0 to $1.00=$ mild stress, 1.01 to $2.00=$ moderate to high stress, 2.01 to $3.00=$ severe stress

Based on the results, it is proved that the major source of stress experienced by the students was related to academic requirements that were represented by ARS, showing the highest mean degree off 2.0453.

Table No 3

Mean and standard deviation of 20 items scale

\begin{tabular}{|l|l|l|l|}
\hline & $\mathrm{N}$ & Mean & Std. Deviation \\
\hline $\begin{array}{l}\text { tests/examinations } \\
\text { falling behind in reading } \\
\text { schedule }\end{array}$ & 243 & 2.43 & .861 \\
$\begin{array}{l}\text { large amount of content to be } \\
\text { learnt }\end{array}$ & 243 & 2.20 & .856 \\
\hline
\end{tabular}




\begin{tabular}{|c|c|c|c|}
\hline $\begin{array}{l}\text { lack of time to review what } \\
\text { have been learnt }\end{array}$ & 243 & 2.74 & .772 \\
\hline heavy workload & 243 & 3.13 & .806 \\
\hline $\begin{array}{l}\text { participation in class } \\
\text { presentation }\end{array}$ & 243 & 1.74 & .962 \\
\hline need to do well & 243 & 1.77 & .970 \\
\hline feeling of incompetence & 243 & 1.79 & 1.024 \\
\hline $\begin{array}{l}\text { unable to answer questions } \\
\text { from patients }\end{array}$ & 243 & 1.44 & 1.098 \\
\hline $\begin{array}{l}\text { talking to patients about } \\
\text { personal problems }\end{array}$ & 243 & 1.63 & 1.119 \\
\hline $\begin{array}{l}\text { facing illness or death of the } \\
\text { patients }\end{array}$ & 243 & 1.81 & 1.039 \\
\hline $\begin{array}{l}\text { verbal or physical abuse by } \\
\text { other students }\end{array}$ & 243 & 1.30 & 1.023 \\
\hline $\begin{array}{l}\text { verbal or physical abuse by } \\
\text { teachers }\end{array}$ & 243 & 1.89 & 1.104 \\
\hline $\begin{array}{l}\text { verbal or physical abuse by } \\
\text { personnel }\end{array}$ & 243 & 1.27 & 1.083 \\
\hline conflict with teachers & 243 & 2.07 & 1.036 \\
\hline $\begin{array}{l}\text { unwillingness to study } \\
\text { medicine }\end{array}$ & 243 & 1.46 & 1.057 \\
\hline $\begin{array}{l}\text { parental wish for you to } \\
\text { study medicine }\end{array}$ & 243 & 1.78 & 1.160 \\
\hline $\begin{array}{l}\text { not enough feedback from } \\
\text { teachers }\end{array}$ & 243 & 1.48 & .920 \\
\hline $\begin{array}{l}\text { uncertainty of what is } \\
\text { expected from me }\end{array}$ & 243 & 1.77 & .990 \\
\hline $\begin{array}{l}\text { lack of recognition for work } \\
\text { done }\end{array}$ & 243 & 1.81 & .955 \\
\hline
\end{tabular}

The highest mean degree of stress was caused by "Heavy workload", with mean degree of 3.13 indicating high to severe stress. Followed by "large amount of content to be learnt", "lack of time to review what have been learnt", and "Tests/Examinations". All these top stressors belong to ARS group. The lowest mean degree of stress was 1.27 related to "verbal or physical abuse by personnel" that belongs to IRS factor.

Overall, the mean stress level ranged between 1 and 4, indicating that the stress level among undergraduate medical students ranged between mild to severe stress. The study revealed that most of the stress is related to ARS factor.

The interpretation of results for each stressor group, along with their relationship with gender variation and level of academic year are discussed individually as follows;

\section{ARS}

The stressor items included within the ARS factors are considered as the main cause of stress among undergraduate medical students. "Heavy workload" with a mean value of 3.13 is the leading cause of stress, whereas "falling behind in reading schedule" with a mean value of 2.20 remained the lowest in this group. Analysis of data revealed that out of 120 females, 11(9.1\%) feels mild stress, $70(58.5 \%)$ feels moderate 
stress and 39(32.5\%) feels severe stress related to academic requirements. On the other hand, out of 123 males 36(29.2\%) feels mild stress, 68(55.2\%) feels moderate stress and 19(15.4\%) feels severe stress. Pearson's value of .283 indicates a weak relationship between gender and stress.

The degree of stress related to ARS; in different levels of academic years remain almost the same. Although a mild reduction of stress is seen from first year to final year. Pearson's $\mathrm{R}$ value of .358 indicates a moderately signification correlation between the two variables.

\section{GARS}

The leading cause of stress related to this group is "feeling of incompetence" with a mean value of 1.79. $34(28.3 \%)$ out of 120 females feel mild stress, 76(63.3\%) feels moderate stress and 10(10\%) feels severe stress while participating in group activities. Whereas, 62(50.4\%) out of 123 males feel mild stress, $56(45.5 \%)$ feel moderate stress and 5(4\%) feel severe stress in performing group activities. Pearson's R value of .224 does not indicate a significant correlation between stress and gender variation.

Group activity related stress significantly reduces with each progressing level of academic year. Pearson's $\mathrm{R}$ value of .316 indicates a moderately significant correlation between these two variables.

\section{SRS}

This factor has got the highest degree of stress related to "facing illness or death of patients" with a mean value of 1.81 .

Out of 120 females, $46(38.3 \%)$ feels mild stress, $70(58.3 \%)$ feels moderate stress and $4(3.3 \%)$ feels severe stress while socializing with patients. $72(58.5 \%)$ out of 123 males feels mild stress when interacting with patients, 43(34.9\%) feels moderate stress and 8(6.5\%) feels severe stress. Pearson's R value of.145 indicates a weak correlation.

Social related stress also shows a progressive reduction from first year to final year. Pearson's R value of .356 indicates that these two variables have got a moderately significant correlation with each other.

\section{IRS}

"Conflict with teachers" is the most common stressor of this group showing a mean value of 2.07, whereas "verbal or physical abuse by personal" remained a least affective stressor.

Out of 120 females, 26(21.6\%) feels mild stress, 83(69.1\%) feels moderate stress and 11(9.1\%) feels severe stress in issues related to interpersonal and intrapersonal matters. On the other hand, 60(48.7\%) out of 123 males feels mild stress, 56(45.5\%) feels moderate stress and 7(5.6\%) feels severe stress in these matters. Pearson's R value of .259 indicates a moderately significant correlation of this stress factor with gender variation.

Interpersonal and intrapersonal related stress domain also indicates a moderately significant correlation with level of academic year by showing progressive reduction of stress level from 1st year to final year and a Pearson's value of .321.

\section{DRS}

This stressor group has got least contribution in developing stress among undergraduate medical students. Out of 120 females, 44(36.6\%) feels mild stress, 61(50.8\%) feels moderate stress and 15(12.5\%) feels severe stress related to desire and drive related stress domain. Out of 123 males 54(43.9\%) feel mild stress, 46(37.3\%) feels moderate stress and 23(18.6\%) feels severe stress. Pearson's R value of.007 indicates a very weak correlation between gender variations and stressors related to desire and drive.

Stress levels related to this domain are higher in 1st year than final year. Pearson's R value of .478 indicates a significant correlation between these two variables. 


\section{TLRS}

The stressors included in this group cause mild too moderate stress in students. The Leading cause is "lack of recognition for work done." with a mean value of 1.81 .

Out of 120 female students, 37(30.8\%) feels mild stress, 78(65\%) feels moderate stress and 5(4.1\%) feels severe stress related to teaching and learning matters. 63(51.2\%) out of 123 males feels mild stress, $56(45.5 \%)$ feels moderate stress and 4(3.2\%) feels severe stress. Pearson's R value of 192 does not indicate a significant correlation between gender variation and teaching and learning related stress domain.

Teaching and learning related stress remains the same from 1st year to final year. Pearson's R value of .185 indicates a weak correlation between TLRS and level of academic year.

\section{Discussions}

This study concluded that Undergraduate medical students experience mild to severe stress during their stay in a medical school. Out of 243 respondents, 138(56.7\%) feels moderate to high stress, whereas 58(23\%) of the respondents feels severe stress related to academic requirements. Studies performed in Malaysia (Saiful, Bahri, Fuad, \& Y, 2009), India (Mehrotra \& Devarakonda, 2015) and Iran (Khanehkeshi, 2011) generated similar results and concluded that academic related stress is the leading cause of stress among undergraduate medical students. Studies also revealed that academic stress is an integral part of medical training as it proves to be a stimulator and a source of positive reinforcement for students to do well in the medical training(Salam et al., 2013). Contrary to this, another study proved that, academic stress and academic performance are inversely related to each other. Increased academic stress not only cause damage to student's health (physical and psychological) but also affects their academic performance (Kormi-nouri, Macdonald, Farahani, Trost, \& Shokri, 2015).

The study also proved that stress has no significant correlation with gender. This fact is supported by the other studies performed internationally (Mehrotra \& Devarakonda, 2015)(Baldassin et al., 2008)(Amr, Hady, Gilany, \& El-hawary, 2008). This study proved that; female students reported a slightly higher level of stress compared to males in all domains. However, this difference was not statistically significant. In addition, gender was not a significant factor in stress reporting, as mean number of stressors was similar in both male and female students.

The analysis of data proved that the level of stress related to academic factors remains the same with insignificant difference from $1^{\text {st }}$ year to final year. Whereas, stress caused by IRS, DRS, TLRS and GARS factors showed a progressive and significant reduction from $1^{\text {st }}$ year to final year. Another study performed in India showed similar results (Mehrotra \& Devarakonda, 2015). Another research proved that stress related to social, interpersonal and intrapersonal factors reduces I the clinical years due to increased interaction with the patients(Firth, 1986).

\section{Conclusion}

This study proved that the leading cause of stress in undergraduate medical students is academics followed by interpersonal and intrapersonal factors. The students feel mild to severe degree of stress during 5 years training. Academics related stress is essential to some extent in order to motivate and reinforce the students. But this should not exceed the limits to cause adverse physical and psychological effects on students.

\section{Limitations}

Self- reported information was accorded through conducting a cross-sectional study. The information was collected around one single point and found potential bias due to understanding of questions by the students according their emotions or it might be occurred due to response inaccuracy. The generalizability of the results may also be affected because study was conducted in only one medical college. 


\section{Acknowledgements}

Thanks to all students of Independent Medical College, who participated in this study to complete the research.

\section{References}

Amr, M., Hady, A., Gilany, E., \& El-hawary, A. (2008). Does Gender Predict Medical Students ' Stress in Mansoura, Egypt?, 1-8. Retrieved from https://www.ncbi.nlm.nih.gov/pmc/articles/PMC2779606/pdf/MEO-13-0273.pdf

Baldassin, S., Correa, T., Ferraz, D. T., De, A. G., Antonio, L., \& Martins, N. (2008). The characteristics of depressive symptoms in medical students during medical education and training : a cross-sectional study. BMC Medical Education, 8(1), 1-8. http://doi.org/10.1186/1472-6920-8-60

Brey, R. A., \& Clark, S. E. (2012). The Wheels of Stress Go ' Round and ' Round. The Health Educator, 44(2), 18-21.

Çivitci, A. (2015). The Moderating Role of Positive and Negative Affect on the Relationship between Perceived Social Support and Stress in College Students. Educational Sciences: Theory and Practice, 15(3), 565-573. http://doi.org/10.12738/estp.2015.3.2553

Firth, J. (1986). Levels and sources of stress in medical students. British Medical Journal (Clinical Research Edition, 292(6529), 1177-1180.

Khanehkeshi, A. L. I. (2011). The Relationship Of Academic Stress With Aggression, Depression And Academic Performance of College Students in Iran. Journal of Educatioanl Psychology, 5(1), 24-31

Kormi-nouri, R., Macdonald, S., Farahani, M., Trost, K., \& Shokri, O. (2015). Academic Stress as A Health Measure and Its Relationship to Patterns of Emotion in Collectivist and Individualist Cultures : Similarities and Differences. International Joural of Higher Education, 4(2), 92-104. http://doi.org/10.5430/ijhe.v4n2p92

Mehrotra, S., \& Devarakonda, S. (2015). Stress In Undergraduate Medical Education : A Cross-Sectional Study. International Jouranl of Recent Scientific Research, 6(4), 3497-3500.

Nandi, M., Hazra, A., Sarkar, S., \& Mondal, R. (2012). Original Article Stress And Its Risk Factors In Medical Students : An Observational Study From A Medical College In India. Indian Jouranl of Medical Sciences, 66(1), 1-12.

Ongori_ERR4_2009.pdf. (n.d.).

Angori, H., and Agolla, J. E. (2009). An Assessment of Academic Stress Among Undergraduate Students: The Case Of University Of Botswana. Education Research and Review, 4(2), 63-70

Saiful, M., Bahri, Y., Fuad, A., \& Y, M. J. (2009). Prevalence and Sources of Stress among Universiti Sains Malaysia Medical Students. Malasyian Journal of Medical Sciences, 17(1), 30-37

Salam, A., Yousuf, R., Muhammad, S., Bakar, A., \& Haque, M. (2013). Stress among Medical Students in Malaysia: A Systematic Review of Literatures. International Medica Journal, 20(6), 649-655.

Solanky, P., Desai, B., Kavishwar, A., \& Kantharia, S. L. (2012). Research Article Study Of Psychological Stress Among Undergraduate Medical Students Of Government Medical College, SURAT. International Jouanl of Medica Science and Public Health, 1(2), 38-42. 